\author{
Н. М. Якуш \\ Белорусский государственный технологический университет
}

\title{
СОВЕРШЕНСТВОВАНИЕ СИСТЕМЫ ТЕХНИЧЕСКОЙ ПОДГОТОВКИ РАБОЧИХ КАДРОВ ДЛЯ СЕЛЬСКОГО ХОЗЯЙСТВА БЕЛОРУССКОЙ ССР (1976-1985 ГГ.)
}

\begin{abstract}
В статье отражены основные формы и методы совершенствования системы технической подготовки рабочих кадров для агропромышленного комплекса Белорусской ССР. Обращено внимание на вопросы технического оснащения учебной базы в сельской общеобразовательной школе, получение школьниками конкретных трудовых навыков и профессиональной механизаторской подготовки. Проанализированы вопросы повышения уровня квалификации по профессиям и специальностям, получаемым учащимися сельских профессионально-технических училищ. Выделены моменты создания средних сельских ПТУ, модернизации и коренной перестройки на их основе всего учебно-воспитательного процесса. Приведены убедительные примеры интенсификации образовательного пространства в лучших учебных заведениях за счет внедрения технических комплексов обучения и расширения спектра общеобразовательных знаний. Рассмотрены направления укрепления учебно-материальной базы и поиска эффективных форм курсовой подготовки сельскохозяйственных рабочих и их переподготовки для работы на новой технике и механизмах. Подчеркнуты определенная взаимосвязь и преемственность ступеней профессионального образования молодых сельскохозяйственных рабочих, перестройка системы их подготовки с учетом научных перспектив развития агропромышленного комплекса республики.
\end{abstract}

Ключевые слова: профессиональная подготовка, квалификация, технический всеобуч, ССПТУ, обучающий комплекс, курсы.

Для цитирования: Якуш Н. М. Совершенствование системы технической подготовки рабочих кадров для сельского хозяйства Белорусской ССР (1976-1985 гг.) // Труды БГТУ. Сер. 6, История, философия. 2021. № 2 (251). С. 34-38.

\author{
N. M. Yakush \\ Belarusian State Technological University
}

\section{IMPROVEMENT OF THE SYSTEM OF TECHNICAL TRAINING OF WORKERS PERSONNEL FOR AGRICULTURE OF THE BELARUSIAN SSR (1976-1985)}

The article reflects the main forms and methods of improving the system of technical training of workers for the agro-industrial complex of the Belarusian SSR. Attention is paid to the issues of technical equipment of the educational base in a rural secondary school, the acquisition of specific labor skills and professional mechanistic training by schoolchildren. The issues of improving the level of qualification in the professions and specialties received by students of rural vocational schools are analyzed. The moments of creating medium-sized rural vocational schools, modernization and radical reconstruction of the entire educational process on their basis are highlighted. Convincing examples of the intensification of the educational space in the best educational institutions due to the introduction of technical training complexes and the expansion of the range of general education knowledge are given. The directions of strengthening the educational and material base and searching for effective forms of course training of agricultural workers and their retraining to work on new equipment and mechanisms are considered. A certain interrelation and continuity of the stages of professional education of young agricultural workers, the restructuring of their training system taking into account the scientific prospects for the development of the agro-industrial complex of the republic are emphasized.

Key words: professional training, qualification, technical general education, SSPTU, training complex, courses.

For citation: Yakush N. M. Improvement of the system of technical training of workers personnel for agriculture of the Belarusian SSR (1976-1985). Proceedings of BSTU, issue 6, History, Philosophy, 2021, no. 2 (251), pp. 34-38 (In Russian).

Введение. Главным содержанием аграрной политики БССР в период середины 1970-х середины 1980-х годов стал перевод сельского хозяйства на принципиально новый научно-технический и организационный уровень, обеспечивающий создание прочной продовольственной базы, повышение благосостояния народа и экономических возможностей республики. 
Соответствующие цели и задачи были сформулированы решениями XXVIII, XXIX съездов Компартии Белоруссии и конкретизированы в заданиях десятого и одиннадцатого пятилетних планов развития народного хозяйства Белорусской ССР. В рассматриваемый период происходили принципиальные перемены в развитии колхозно-совхозного производства. Разворачивались процессы межхозяйственной кооперации и агропромышленной интеграции, углублялись специализация и концентрация производства, которые способствовали формированию такой производственно-экономической системы, как агропромышленный комплекс. Происходящие изменения сделали крайне важной задачу обеспечения сельского хозяйства рабочими кадрами, профессионально подготовленными для работы в условиях интенсивно развивающегося производства и обладающими новой технологической культурой. Для ее решения были осуществлены крупные меры по созданию и совершенствованию системы подготовки механизаторских кадров массовых профессий, обеспечивающей условия для получения высокой технической квалификации и предоставляющей возможность сельским труженикам систематически повышать уровень профессионального мастерства.

Основная часть. База для повышения технического уровня профессиональной квалификации рабочих кадров села закладывалась в процессе перестройки образовательного пространства средней школы и сельских профессионально-технических училищ (СПТУ). Советская школа за годы своего существования накопила большой опыт по воспитанию молодежи, ее подготовке к активному участию в общественной и трудовой жизни. В рассматриваемый период развитие системы народного образования в СССР определялось требованиями научнотехнического прогресса, что усиливало политехнизацию учебного процесса. Партийные и хозяйственные органы, педагогические коллективы Белорусской ССР сделали решительный поворот к улучшению подготовки школьников к труду в сфере материального производства, обоснованного выбора ими профессии. Комплекс мер в этом направлении включал в себя создание соответствующей материальной базы, улучшение профессиональной и идейной подготовки учителей, разработку новых учебных программ и методических пособий, обеспечивающих реализацию принципа политехнического образования.

Характерным моментом периода 19761985 гг. является установление шефских связей и заметное расширение контактов трудовых коллективов колхозов, совхозов, близлежащих предприятий с сельскими школами и их сотрудничество в вопросах совершенствования учебного процесса, создания стационарных лагерей труда и отдыха. Совместные усилия были направлены на совмещение производственных интересов хозяйств и педагогических интересов учащихся. Ставилась задача становления в школе допрофессиональной и профессиональной подготовки механизаторов. Финансовая помощь со стороны производства и непосредственное организационное участие хозяйств в реализации комплексной программы трудовой подготовки школьников способствовали упрочению учебно-материальной базы сельских школ. Заметно расширились площади пришкольных учебно-опытных участков, проводилось переоборудование кабинетов обслуживающего труда, учебных мастерских, велось строительство теплиц, трактородромов, кабинетов механизации сельского хозяйства и профессиональной ориентации по основам сельскохозяйственной техники, городков по правилам дорожного движения [1].

К началу 1980-х гг. в сельских школах республики уже определились теоретическая основа и практическая база углубленного трудового обучения специальностям агропромышленного комплекса. Плодотворно велась работа в таком направлении в Мостовском, Рогачевском, Солигорском, Столинском районах. В лучших школах этих районов были созданы возможности для изучения тракторов, освоения новых видов техники, технологии механизированных работ и основ агротехники полевых культур [2]. Активные поиски по усилению технической составляющей образовательного процесса привели к решению повсеместного создания в сельской местности межшкольных учебно-производственных комбинатов (УПК) трудового обучения и профессиональной ориентации. Именно сельские УПК в рассматриваемый период выступили новой формой политехнизации общеобразовательной школы, усиления ее социально-экономической и научно-культурной роли.

Однако основным направлением работы по формированию у школьников готовности и стремления к сельскохозяйственному труду выступала ориентация их на дальнейшее обучение в сельских профессионально-технических училищах (СПТУ). В исследуемое время именно они выступили наиболее целесообразной формой обучения рабочих кадров агропромышленного комплекса. Складывающаяся новая производственно-экономическая система аграрного сектора требовала от выпускника сельских ПТУ технической грамотности, высокой квалификации, широкого агро- и зоотехнического кругозора наряду с общеобразовательной подготовкой. Решение этой задачи предполагалось на путях количественного и качественного роста 
профтехучилищ с учетом значительного увеличения количества средних СПТУ, кардинальной технической модернизации их материальноучебной базы, перехода на обучение молодежи профессиям широкого профиля, совмещенным и сложным, повышения уровня квалификации педагогических кадров. Планировались такие темпы развития сети училищ, чтобы в перспективе в каждом административном районе имелось современное технически оснащенное сельское среднее ПТУ. На эти цели только в 19761985 годах было выделено 91,7 млн. рублей капитальных вложений [3].

В исследуемый период осуществлялась значительная по масштабам и темпам программа строительства и реконструкции СПТУ, их оснащения современной сельскохозяйственной техникой и оборудованием, совершенствования учебной базы теоретического и производственного обучения, исходя из требования: для каждой профессии - учебная мастерская, для каждого предмета - учебный кабинет или лаборатория. С 1 сентября 1984 года в соответствии с основными направлениями реформы общеобразовательной и профессиональной школы сельские профессионально-технические училища были преобразованы в средние и включены в агропромышленные объединения. Качественные изменения процесса обучения демонстрировали те СПТУ, в которых инженерно-педагогические коллективы совместно с базовыми хозяйствами вели эту работу системно и творчески. В качестве примера можно назвать Смиловичское СПТУ. В нем только за 1978 год было оборудовано техническими средствами обучения с рабочим местом для преподавателя 27 учебных кабинетов, реконструировано 9 лабораторий для проведения лабораторно-практических занятий по 10-звеньевой системе с полным комплексом изучаемых машин и узлов к ним, изготовлено 76 единиц наглядных пособий, значительно укрепилась база учебного хозяйства. По качеству подготовки сельскохозяйственных рабочих училище было признано образцовым в Минской области, а по итогам Всесоюзного социалистического соревнования в 1981 году оно названо лучшим в СССР среди учебных заведений мелиоративного профиля. Инициативно решался вопрос модернизации учебно-производственной базы коллективом Борисовского СПТУ № 25, в котором для руководства работой по переоборудованию кабинетов, цехов и мастерских в 1976 году была создана группа научной организации труда (НОТ). Под ее началом в течение двух лет большинство классов теоретического обучения были переоборудованы в соответствии с требованиями профессиональной подготовки, снабжены необходимыми учебными средствами.
В дальнейшем группа принимала меры по созданию условий обучения профессии слесаря контрольно-измерительных приборов и автоматики, а также совершенствованию базы подготовки механизаторов-мелиораторов с учетом требований технической эстетики и научной организации труда [4].

Совершенствование процесса теоретического обучения в средних сельских профтехучилищах нашло отражение в учебных планах, введенных с начала 1978/1979 учебного года. Они предусматривали тесную взаимосвязь изучения общеобразовательных дисциплин с дисциплинами общетехническими и специальными, а также с производственным обучением. В профессионально-технический цикл вводился курс «Основы экономики труда и производства». В курсе специальной технологии кроме материала, связанного с профессией, стали изучаться такие технические темы, как сопротивление материалов, технический контроль, детали машин, вопросы теории машин и механизмов, технический контроль, надежность и качество продукции, сведения по механизации и автоматизации производства, вопросы техники, основы гигиены и промышленной санитарии. Эти знания обеспечивали повышение квалификационного уровня и расширение технического кругозора в рамках получаемых специальностей, увеличивали профессиональную мобильность выпускников.

Вместе с изменением научно-теоретической основы учебного процесса менялся и характер обучения. Решающими становились методы, обеспечивающие развитие познавательной деятельности, творчества и технической инициативы самих учащихся. Огромную роль в пробуждении технической мысли учащихся сыграло активное включение СПТУ Белорусской ССР во Всесоюзный смотр-конкурс на лучшую постановку работы в области рационализации, изобретательства, технического и художественного творчества в учебных заведениях профессионально-технического образования. Конкурс активизировал кружковую и выставочную деятельность сельских ПТУ. Экспонаты, демонстрируемые на выставках СПТУ, были в основном действующими моделями сельскохозяйственной техники и всевозможных тренажеров различных ее узлов. Так, на юбилейной выставке технического творчества учащихся ПТУ в 1979 году были представлены сработанная руками учащихся сельских профтехучилищ электрофицированная модель трактора Т-150 и модель комбайна «Нива», экскаватор Э-652 и шагающий экскаватор, электрооборудование для тракторов МТ3-50 и МТ-80, гидроусилитель рулевого управления комбайна СК-4А [5]. Многие из разрабатываемых моделей, особенно из числа 
автоматических справочных установок, активно использовались в самом процессе обучения.

В решающей степени качественное изменение образовательного пространства в СПТУ определялось изменением квалификационно-профессионального состава инженерно-педагогических кадров училищ. В исследуемый период педагогические кадры сельских профессиональнотехнических училищ пополнились значительным количеством выпускников инженерно-технических и педагогических вузов республики. Была налажена система постоянного повышения профессионального мастерства. В соответствии с планами повышения квалификации за 1975-1985 гг. было переподготовлено преподавателей специальных дисциплин и мастеров производственного обучения сельских ПТУ в Белорусском институте механизации и электрификации сельского хозяйства - 460 человек, на Западной машиноиспытательной станции - 528, на заводах-изготовителях сельскохозяйственной техники - 578, в Горецкой сельскохозяйственной академии - 70 человек. Кроме того, 1600 мастеров производственного обучения повысили свое мастерство в республиканском институте повышения квалификации работников профтехобразования, а преподаватели общеобразовательных дисциплин - в республиканском и областных институтах усовершенствования учителей [6]. Возможности повышения квалификационного уровня педагогов создавались и непосредственно в самих учебных заведениях.

Несмотря на несомненные положительные достижения сельских профтехучилищ в вопросах создания реальной основы подготовки технически грамотного, с высокой общеобразовательной подготовкой сельскохозяйственного рабочего, оставалось и значительное количество вопросов проблемного характера. Так, учебноматериальная база во многих училищах не соответствовала требованиям подготовки высококвалифицированных специалистов, наблюдались диспропорции в ее уровнях развития в разрезе отдельных профессий, а сам процесс совершенствования материально-технического обеспечения учебного процесса проходил без должного учета необходимости расширения женских профессий и вопросов специализации СПТУ. В составе инженерно-педагогических кадров среди мастеров производственного обучения был высок процент практиков, не имеющих специального образования, а молодые преподаватели общеобразовательных дисциплин выпускники вузов были слабо ориентированы и подготовлены для работы в профтехучилищах.

Острая нехватка механизаторов и квалифицированных сельскохозяйственных рабочих в колхозно-совхозном производстве привлекла пристальное внимание партийных, советских и хозяйственных органов республики к вопросам курсовой подготовки кадров массовых профессий. В исследуемые годы было подготовлено и утверждено отраслевое положение о профессиональном обучении сельскохозяйственных рабочих и нормативы на создание учебно-производственной базы. В итоге проведенной работы к 1985 году была создана разветвленная сеть курсового обучения. Она включала 1 республиканский, 6 областных и 1 межрайонный (на базе Несвижской райсельхозтехники) хозрасчетный учебно-курсовой комбинат, 117 учебных пунктов районных объединений сельхозтехники, насчитывающие 509 классов на 13587 посадочных мест, классы и кабинеты в колхозах и совхозах на 11520 ученических мест [7].

Система курсов обеспечивала подготовку рабочих таких массовых профессий, как тракторист-машинист, водитель автомобиля, комбайнер, машинист дождевальных поливных машин и машинист насосных установок, газоэлектросварщик, операторы по приготовлению и раздаче кормов, по выращиванию крупного рогатого скота, по производству свиней, по очистке, активному вентилированию и сушке зерна. Велась подготовка слесарей по ремонту и наладке оборудования, сантехники и др. Кроме того, учебные центры Госкомсельхозтехники обеспечивали повышение квалификации механизаторских кадров, изучение ими новой энергонасыщенной техники и передовой технологии сельскохозяйственного производства. Учебный процесс осуществляли методисты, мастера производственного обучения и преподаватели из числа специалистов и руководящих работников Госкомсельхозтехники. Для преподавания на курсах в колхозах и совхозах привлекались специалисты сельскохозяйственного производства, преподаватели вузов, техникумов, сельских профтехучилищ, передовики производства. В каждом сельском районе республики была введена должность по техническому всеобучу населения.

Инженерно-педагогические кадры, осуществлявшие курсовую подготовку рабочих кадров массовых профессий для села, систематически совершенствовали свои знания и опыт. Повышение их мастерства осуществляли Всесоюзный институт повышения квалификации руководящих работников Госкомсельхозтехники СССР и республиканский институт повышения квалификации работников профтехобразования, республиканский и областные учебные комбинаты, а также школы передового опыта.

Стояла задача оснащения сети районных и областных отделений сельхозтехники новейшими средствами обучения и самым современным оборудованием, создания при каждом пункте 
методических кабинетов, организации полностью механизированных учебных классов, особенно передвижных классов на базе автомобилей ЛАЗ и «Москвич» для занятий с животноводами. Положительные примеры ее решения демонстрировала Гродненская область. Так, в 1979 году учебно-производственный пункт Слонимской райсельхозтехники располагал общим классом на 42 места с полной механизацией, классом-цехом для подготовки специалистов животноводческих ферм, полностью механизированным отдельным классом для подготовки водителей. Кроме того, в учебном пункте имелся методический кабинет, оборудованный в соответствии с требованиями научной организации труда, работал методический совет из двенадцати специалистов и наставников молодежи. Все это позволило добиться высоких темпов и качества подготовки сельскохозяйственных ра- бочих. Государственный Комитет Сельхозтехники Белорусской ССР создал на его базе школу передового опыта [8].

Заключение. Таким образом, совершенствование системы технической подготовки рабочих кадров для села в Белорусской ССР в 19761985 годах проводилось, во-первых, на основе дальнейшей политехнизации сельской общеобразовательной школы, углубленного трудового обучения школьников сельскохозяйственным профессиям и его связи с производительным трудом; во-вторых, за счет качественной модернизации учебно-производственной базы и интенсификации процесса обучения в сельских профтехучилищах; в-третьих, на базе формирования разветвленной сети курсовой подготовки и переподготовки кадров массовых сельскохозяйственных профессий с современной учебно-материальной базой и централизованным методическим руководством.

\section{Список литературы}

1. Настаўніцкая газета. 1978. 30 чэрвеня.

2. Национальный архив Республики Беларусь (НАРБ). Ф. 4. Оп. 1. Д. 61. Л. 9-15.

3. НАРБ. Ф. 4. Оп. 125. Д. 64. Л. 27-30, 76, 82.

4. НАРБ. Ф. 4. Оп. 1. Д. 33. Л. 41-43; Д. 23. Л. $12,91$.

5. НАРБ. Ф. 4. Оп. 75. Д. 32. Л. 21, 23, 56-61.

6. НАРБ. Ф. 4. ОП. 1. Д. 30. Л. 121; Д. 34. Л. 49-51.

7. НАРБ. Ф. 4. Оп. 79. Д. 4. Л. 16-20.

8. Сельская газета. 1979. 13 ноября.

\section{References}

1. Nastaunitskaya gazeta [Teachecs newspaper]. 1978, June 30.

2. National Archives of the Republic of Belarus (NARB). Fund 4. I. 1. F. 61. L. 9-15.

3. NARB. Fund 4. I. 1. F. 64. L. 27-30, 76, 82.

4. NARB. Fund 4. I. 1. F. 33. L. 41-43; F. 23. L. 12, 91.

5. NARB. Fund 4. I. 75. F. 32. L. 21, 23, 56-61.

6. NARB. Fund 4. I. 1. F. 30. L. 121; F. 34. L. 49-51.

7. NARB. Fund 4. I. 79. F. 4. L. 16-20.

8. Sel'skaya gazeta [Rurals newspaper]. 1979, November 30.

\section{Информация об авторе}

Якуш Надежда Михайловна - кандидат исторических наук, доцент, доцент кафедры истории Беларуси и политологии. Белорусский государственный технологический университет (220006, г. Минск, ул. Свердлова, 13a, Республика Беларусь). E-mail: yakush@belstu.by

\section{Information about the author}

Yakush Nadzezhda Mikhailovna - PhD (History), Associate Professor, Assistant Professor, the Department of History of Belarus and Political Science. Belarusian State Technological University (13a, Sverdlova str., 220006, Minsk, Republic of Belarus). E-mail: iackush@yandex.ru 